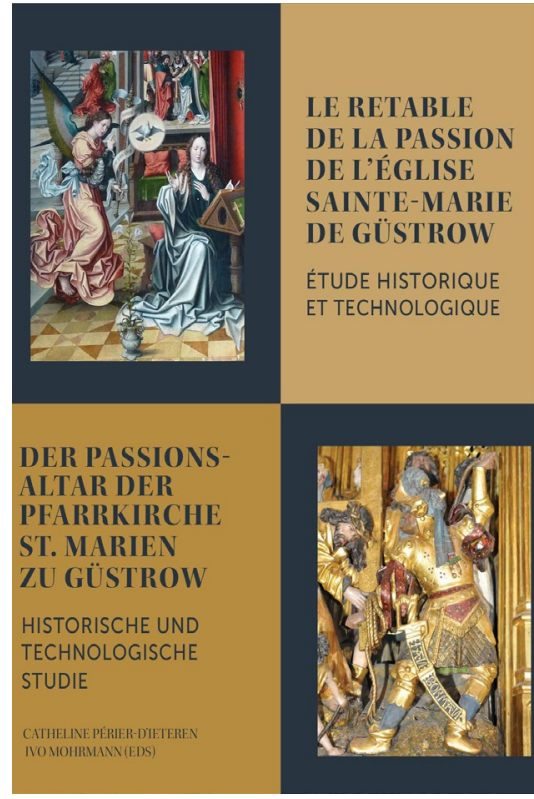

Este libro es la primera monografía dedicada al Retablo de la Pasión de la Iglesia de Santa María de Güstrow en Alemania, importante aunque poco conocido retablo brabanzón de comienzos del s. XVI. Obra mixta, con cuerpo de escultura policromada y doble par de puertas (las interiores talladas, las exteriores pintadas), está firmado "Ian Borman", lo que lo sitúa dentro de la producción de este taller de escultores, autores de numerosos y sobresalientes ejemplares dedicados a la exportación. Las puertas pintadas, atribuidas al entorno de Bernard van Orley, maestro de primer nivel de la escuela de Bruselas de pintura, contribuyen a su calidad.

La publicación, en versión bilingüe (francés y flamenco) y editada por el centro de difusión de la Universidad libre de Bruselas, es una obra colectiva escrita por trece autores bajo la dirección de C. Périer- d'leteren y la colaboración de I. Morhmann. Se estructura en cuatro grandes capítulos, cada uno de ellos a su vez dividido en varios apartados:

\section{Capítulos de introducción}

C. Périer d'leteren describe esta tipología de retablos con doble par de puertas y su importancia dentro de la producción de los retablos brabanzones de los siglos XV y XVI. B. D'Hainaut-Zveny reflexiona sobre el uso y la función de esta disposición formal de puertas pintadas y talladas. L. Vogel aporta la historia particular y el contexto histórico del retablo y T. Schöfbeck \& K.$U$. Heußner el sorprendente resultado de los análisis
Le Retable de la Passion de l'Eglise Saint-Marie de Güstrow - Etude historique et technologique. Der Passions-Altar der Pfarrkirche St. Marien zu Güstrow - Historische und technologische Studie

\author{
Perier-D'leteren, Catheline; Ivo Mohrmann (eds)
}

Editechnart, A.S.B.L. Editions \&diffusion du centre technologique de I'ULB. Bruselas, 2014

Páginas: 255

llustraciones en color

$29 \times 23 \mathrm{~cm}$.

ISBN 9789461360458 dendrocronológicos, que posponen la fecha de ejecución habitualmente admitida y revelan la utilización puntual de madera local.

\section{Pinturas}

V. Büchen estudia las puertas pintadas del retablo y la figura del pintor Bernard van Orley y C. Périer d'leteren, basándose en el estudio subyacente y en similitudes estilísticas, propone la participación de diversos maestros en su realización; I. Mohrmann y K. Riße aportan las pruebas científicas realizadas in situ: radiografías, reflectografía infrarroja y fluorescencia ultravioleta y $B$. Jackisch el análisis tecnológico de las pinturas.

\section{Esculturas}

H. Nieuwdorp presenta sugerentes consideraciones sobre los Borman, sus posibles talleres y colaboraciones, mientras que $C$. Périer-d'leteren, a partir del estudio estilístico, atribuye las diversas escenas a Jan III y Passier Borman, así como a un colaborador de este último; $V$. Enlich resume ciertos aspectos técnicos del retablo.

\section{Restauraciones}

$U$. Stehr y $M$. Runge exponen la restauración de las pinturas del retablo, el primero de ellos aludiendo a la figura de Alois Hauser el Viejo, restaurador prestigioso del sigo XIX y finalmente $V$. Enlich relata la intervención sobre la escultura. 
Resumiendo, el libro es fruto del estudio profundo del retablo por parte de un equipo internacional de expertos. Su lectura resulta de interés tanto para historiadores de arte como para conservadores y restauradores, y en general para todas aquellas personas interesadas en los retablos y más particularmente, en los retablos brabanzones. El planteamiento de nuevas líneas de investigación sobre la producción de los talleres y artistas de la época, sus mutuas influencias, colaboraciones y maneras de trabajar, amplía la visión de este mundo complejo y si bien pertenece a un entorno específico, puede permitir su extrapolación a otros ámbitos geográficos.

Maite Barrio Olano

Albayalde Conservatio 